TẠP CHÍ KHOA HỌC ĐẠI HỌC TÂN TRÀO

ISSN: 2354 - 1431

http://tckh.daihoctantrao.edu.vn/

\title{
NGHIÊN CỨU ẢNH HƯỞNG CỦA THỜI ĐIỂM KHOANH VỎ ĐẾN THỜI GIAN RA HOA, TỶ LỆ ĐẬU QUẢ VÀ NĂNG SUẤT BƯởI XUÂN VÂN TỈNH TUYÊN QUANG
}

\author{
Vi Xuân Học ${ }^{1 *}$, Nguyễn Thị Xuyến ${ }^{2}$,Phạm Thị Mai Trang ${ }^{1}$, Nguyễn Thị Thu Hiền ${ }^{1}$ \\ ${ }^{I}$ Truò̀ng Đại học Tân Trào \\ ${ }^{2}$ Trường Cao đẳng kinh tế kỹ thuật Thái Nguyên \\ *Email: hocvibm@gmail.com
}

\section{Thông tin bài viết}

Ngày nhận bài:

21/7/2020

Ngày duyệt đăng:

$12 / 8 / 2020$

Tù khóa:

Khoanh vỏ, tỷ lẹ đâu quả, năng suất bưởi Xuân Vân.

\begin{abstract}
Tóm tắt
Bưởi Xuân Vân có xuất xứ tại xã Xuân Vân huyện Yên Sơn, tỉnh Tuyên Quang, là giống bưởi ngọt chín sớm, có khả năng rải vụ. Hiện nay bưởi Xuân đang được xác định là một trong những cây trồng có thế mạnh của tỉnh Tuyên Quang và có khả năng phát triển ở các tỉnh trung du miền núi phía Bắc. Bưởi Xuân Vân có số lượng hoa tương đối lớn nhưng tỷ lệ đậu quả thấp do trong thời kỳ nở hoa gặp phải những yếu tố bất lợi. Nhằm điều chỉnh quá trình ra hoa và làm tăng tỷ lệ đậu quả, những nghiên cứu về thời điểm khoanh vỏ trên bưởi Xuân Vân cho thấy: Khoanh vỏ vào ngày 25 tháng 12 hàng năm bưởi Xuân Vân đã ra hoa sớm hơn từ 1 - 7 ngày, tăng tỷ lệ đậu quả từ 1,25 đến 1,29\%, năng suất quả thu được đạt cao nhất (118,4 và 120,1 kg/cây), sai khác có ý nghĩa thống kê ở mức tin cậy $95 \%$. Khoanh vỏ vào ngày 25 tháng 12 hàng năm có tác rụng rõ rệt trong việc điều chỉnh thời gian ra hoa, nâng cao tỷ lệ đậu quả, từ đó nâng cao được năng suất bưởi Xuân Vân.
\end{abstract}

\section{1. ĐẶT VẤN ĐỀ}

Khoanh vỏ hay khấc thân cành đã gây ra sự tích lũy những sản phẩm trao đổi chất được tạo ra trên chồi (Carbonhydrate, $A B A$, và Auxin) ở phía trên vết khoanh, những chất đồng hóa (Cytokitin, Gibberellin và đạm) được cung cấp bởi rễ được tích lũy ở dưới vết khoanh, những sản phẩm trao đổi chất này có ảnh hưởng đến sự ra hoa. Khoanh vỏ đã làm phá vỡ tế bào mô libe cho nên đã ảnh hưởng trực tiếp đến sự vận chuyển các sản phẩm đồng hóa trong cây, làm giảm sự cung cấp các sản phẩm đồng hóa và auxin tới rễ, những tác động này đã làm giảm sự hoạt động của bộ rễ, giảm nguồn cung cấp Cytokitin cho chồi. Khoanh vỏ còn có tác dụng làm tăng sự đậu quả trên cây có múi do đặc tính tự bất tương hợp (Self Incompability) hoặc thiếu hạt phấn có sức nảy mầm tốt. Hiện nay trên thế giới và ở Việt Nam đã có nhiều công trình nghiên cứu về ảnh hưởng của khoanh vỏ đến năng suất một số loại cây ăn quả có múi, trong đó đã có rất nhiều công trình khoa học nghiên cứu trên cây bưởi.v.v.. Hầu hết những nghiên cứu đều chỉ ra 
rằng khoanh vỏ đã có tác động tích cực đến tỷ lệ đậu quả, tăng số quả trên cây và cải thiện năng suất quả trên cây có múi và cây bưởi. Tuy nhiên, những nghiên cứu về khoanh vỏ chỉ phù hợp với một số loại cây trồng ở mỗi thời vụ nhất định, có thể có những tác động tích cực hay tiêu cực đến cây ăn quả nói chung cây có múi nói riêng, vì vậy trong thực tiễn sản xuất cần có những thử nghiệm đánh giá trên đồng ruộng lựa chọn những công thức khoanh vỏ phù hợp để khuyến cáo cho sản xuất.

\section{VẠT LIỆ VÀ PHƯƠNG PHÁP NGHIÊN CÚU}

\subsection{Vật liệu, địa điểm và thời gian nghiên cứu}

- Vật liệu nghiên cứu: Giống bưởi Xuân Vân từ 9 10 tuổi ở thời kì kinh doanh ổn định.

- Địa điểm nghiên cứu: Xã Xuân Vân huyện Yên Sơn tỉnh Tuyên Quang.

- Thời gian nghiên cứu: Năm 2018 và năm 2019.

\subsection{Phương pháp nghiên cứu}

- Phương pháp bố trí thí nghiệm: Thí nghiệm được bố trí theo kiểu ngẫu nhiên hoàn chỉnh (RCBD) trên vườn bưởi 9 - 10 năm tuổi, 3 lần nhắc lại, mỗi công thức 3 cây.

- Thí nghiệm gồm các công thức như sau:

+ Công thức 1 : Khoanh cành cấp 2 vào ngày 5 tháng 12.

+ Công thức 2: Khoanh cành cấp 2 vào ngày 15 tháng 12.

+ Công thức 3: Khoanh cành cấp 2 vào ngày 25 tháng 12.
+ Công thức 4: Đối chứng không khoanh.

- Các công thức thí nghiệm được nghiên cứu trong cùng một điều kiện trồng trọt và chăm sóc như nhau. Trên cành cấp 2 dùng dao chuyên dụng khoanh 2 vòng quanh cành, chiều rộng của vết khoanh là $2 \mathrm{~mm}$, chiều sâu vừa đủ chạm tới phần tượng tầng.

- Ngoài các yếu tố thí nghiệm các công thức được chăm sóc theo 1 nền chung: $50 \mathrm{~kg}$ phân chuồng hoai mục +800 gram $\mathrm{N}+400$ gram $\mathrm{P}_{2} \mathrm{O}_{5}+600$ gram $\mathrm{K}_{2} \mathrm{O} /$ cây.

+ Lần 1: Bón $100 \%$ phân lân + 100\% phân chuồng + 20\% phân đạm + $20 \%$ phân kaly bón vào cuối tháng 12 đầu tháng 1 .

+ Lần 2: Bón $40 \%$ phân đạm + $40 \%$ phân kali bón vào tháng 3 .

+ Lần 3: Bón 20\% phân đạm + $20 \%$ phân kali bón vào tháng 5 .

+ Lần 4: Bón 20\% phân đạm + $20 \%$ phân kali bón vào tháng 7 và tháng 8 .

- Chỉ tiêu và phương pháp theo dõi:

+ Thời gian xuất hiện nụ hoa khi cây có $10 \%$ hoa nở.

+ Thời gian nở hoa rộ khi cây có $50 \%$ hoa nở.

+ Thời gian kết thúc nở hoa khi cây có $80 \%$ hoa đã nở.

- Tỷ lệ đậu quả: Trên mỗi cây theo dõi 4 cành phân bố đều về các hướng đếm tổng số hoa trên cành theo dõi. Cứ 10 ngày đếm số quả một lần, đếm số quả đậu ở các cây theo dõi cho đến khi hoa tàn.

$$
\text { Tỷ lệ đậu quả }(\%)=\frac{\text { Số quả đậu }}{\text { số nụ, hoa, quả rụng + quả đậu }} \times 100
$$

- Các yếu tố cấu thành năng suất và năng suất

+ Số quả/cây/công thức (quả): Tổng số quả thu được trong từng công thức/tổng số cây trong mỗi công thức.

+ Khối lượng trung bình quả $(\mathrm{kg})$ : Tổng khối lượng quả trong từng công thức/tổng số quả.

+ Năng suất/cây/công thức $(\mathrm{kg})$ : Số quả $\mathrm{x}$ Khối lượng quả.

- Số liệu thí nghiệm được xử lý thống kê bằng Excel và IRRISTAT 5.0

\section{KẾT QUẢ NGHIÊN CÚ̉U VÀ THẢO LUÂN}

3.1. Ảnh hưởng của thời điểm khoanh vỏ đến đến thời gian ra hoa bưởi Xuân Vân

Số liệu theo dõi tại bảng 01 cho thấy, năm 2018 các công thức khoanh vỏ có thời gian xuất hiện nụ sớm hơn từ 3 - 11 ngày so với công thức đối chứng (không khoanh). Thời gian bắt đầu nở hoa ở các công thức khoanh vỏ sớm hơn công thức đối chứng từ 2 - 4 ngày, thời gian hoa nở rộ sớm hơn đối chứng từ 2 - 7 
ngày, thời gian kết thúc nở hoa cũng sớm hơn đối chứng từ 3 - 7 ngày. Trong các công thức khoanh vỏ, công thức khoanh ngày 25 tháng 12 (công thức 3) có thời gian từ xuất hiện nụ hoa đến kết thúc nở hoa đều sớm hơn so với công thức 1 , công thức 2 và công thức đối chứng (bảng 01). Tương tự như vậy kết quả theo dõi năm 2019 cho thấy, thời gian xuất hiện nụ hoa ở các công thức khoanh vỏ sớm hơn công thức đối chứng từ 1 - 5 ngày, thời gian nở hoa sớm hơn công thức đối chứng từ 2 - 6 ngày, thời gian nở hoa rộ sớm hơn đối chứng từ 1 - 5 ngày, thời gian kết thúc nở hoa sớm hơn từ 1 - 7 ngày. Trong các công thức khoanh vỏ công thức khoanh ngày 25 tháng 12 (công thức 3 ) là công thức có thời gian xuất hiện nụ, nở hoa rộ và kết thúc nở hoa đều sớm hơn so với công thức 1 , công thức 2 và công thức đối chứng.

\section{Bảng 01. Ảnh hưởng của thời điểm khoanh vỏ đến thời gian ra hoa bưởi Xuân Vân} tại huyện Yên Sơn - Tuyên Quang

\begin{tabular}{|c|c|c|c|c|}
\hline \multirow[t]{2}{*}{ Công thức } & \multirow{2}{*}{$\begin{array}{c}\text { Thời gian xuất hiện } \\
\text { nụ (ngày, tháng) }\end{array}$} & \multicolumn{3}{|c|}{ Thò̀i gian nở hoa (ngày, tháng) } \\
\hline & & Bắt đầu & $\boldsymbol{R} \hat{\boldsymbol{\varphi}}$ & Kết thúc \\
\hline \multicolumn{5}{|l|}{ Năm 2018} \\
\hline Công thức 1 & $22-25 / 1$ & $10-13 / 2$ & $17-25 / 2$ & $2-6 / 3$ \\
\hline Công thức 2 & $18-22 / 1$ & $8-13 / 2$ & $15-23 / 2$ & $1-5 / 3$ \\
\hline Công thức 3 & $17-21 / 1$ & $7-13 / 2$ & $14-20 / 2$ & $28 / 2-3 / 3$ \\
\hline Công thức 4 & $25 / 1-2 / 2$ & $10-17 / 2$ & $18-27 / 2$ & $5-8 / 3$ \\
\hline \multicolumn{5}{|l|}{ Năm 2019} \\
\hline Công thức 1 & $27 / 1-9 / 2$ & $12-19 / 2$ & $20 / 2-2 / 3$ & $2-10 / 3$ \\
\hline Công thức 2 & $26 / 1-7 / 2$ & $10-17 / 2$ & $19 / 2-1 / 3$ & $1-8 / 3$ \\
\hline Công thức 3 & $24 / 1-5 / 2$ & $8-16 / 2$ & $17-28 / 2$ & $27 / 2-5 / 3$ \\
\hline Công thức 4 & $28 / 1-10 / 2$ & $14-21 / 2$ & $22 / 2-3 / 3$ & $3 / 3-13 /$ \\
\hline
\end{tabular}

Ghi chú: Công thức 1(khoanh cành cấp 2 vào ngày 5 tháng 12); Công thức 2 (khoanh cành cấp 2 vào ngày 15 tháng 12); Công thức 3(khoanh cành cấp 2 vào ngày 25 tháng 12); Công thức 4 (đối chứng không khoanh)

3.2. Ảnh hưởng của thời điểm khoanh vỏ đến tỷ lệ đậu quả bưởi Xuân Vân

Số liệu theo dõi tại bảng 02 cho thấy, sau 10 ngày tắt hoa các công thức khoanh vỏ đều có tỷ lệ đậu quả cao hơn công thức đối chứng ở mức độ tin cậy $95 \%$. Theo dõi tỷ lệ đậu quả thời điểm sau tắt hoa 10 ngày, 20 ngày, 30 ngày, 40 ngày, 50 ngày và 60 ngày cho thấy (bảng 02), tỷ lệ đậu đều quả giảm dần ở tất cả các công thức bao gồm cả công thức đối chứng. Thời điểm sau tắt hoa 60 ngày công thức công thức khoanh ngày 25 tháng 12 (công thức 3) có tỷ lệ đậu quả cao nhất, đạt tỷ lệ 1,25\% (năm 2018), đạt tỷ lệ 1,29\% (năm 2019) trong khi đó các công thức 1 và công thức 2 có tỷ lệ đậu quả thấp hơn so với công thức 3;

năm 2016 công thức 1 đạt tỷ lệ 1,14 \%, năm 2019 đạt tỷ lệ 1,2\%; công thức 2 năm 2018 đạt tỷ lệ 1,22\%, năm 2019 đạt tỷ lệ 1,24 \%. Năm 2018 công thức đối chứng đạt tỷ lệ đậu quả $0,87 \%$, năm 2019 đạt tỷ lệ đậu quả $0,92 \%$. Các công thức khoanh vỏ có tỷ lệ đậu quả cao hơn công thức đối chứng ở mức tin cậy $95 \%$, trong đó công thức 3 có tỷ lệ đậu quả cao nhất. 
Bảng 02. Ảnh hưởng của thời điểm khoanh vỏ đến tỷ lệ đậu quả bưởi Xuân Vân tại huyện Yên Sơn - Tuyên Quang

\begin{tabular}{|c|c|c|c|c|c|c|}
\hline \multirow{2}{*}{ Công thức } & \multicolumn{6}{|c|}{ Tỷ lệ đậu quả (\%) sau tắt hoa } \\
\hline & $\begin{array}{c}10 \\
\text { ngày }\end{array}$ & $\begin{array}{c}20 \\
\text { ngày }\end{array}$ & 30 ngày & 40 ngày & 50 ngày & 60 ngày \\
\hline \multicolumn{7}{|l|}{ Năm 2018} \\
\hline Công thức 1 & 11,94 & 10,26 & 7,40 & 4,48 & 2,06 & 1,14 \\
\hline Công thức 2 & 12,60 & 10,71 & 8,03 & 5,24 & 3,17 & 1,22 \\
\hline Công thức 3 & 12,56 & 11,2 & 8,80 & 6,31 & 3,78 & 1,25 \\
\hline Công thức 4 & 10,26 & 8,20 & 6,01 & 4,28 & 1,46 & 0,87 \\
\hline$C V(\%)$ & 6,60 & 7,80 & 9,30 & 8,30 & 10,2 & 3,10 \\
\hline$L S D_{0,05}$ & 1,47 & 1,48 & 1,31 & 0,79 & 0,48 & 0,06 \\
\hline \multicolumn{7}{|l|}{ Năm 2019} \\
\hline Công thức 1 & 12,71 & 9,56 & 6,61 & 5,07 & 3,88 & 1,2 \\
\hline Công thức 2 & 12,27 & 9,25 & 6,91 & 5,11 & 3,57 & 1,24 \\
\hline Công thức 3 & 12,08 & 9,48 & 7,30 & 5,46 & 3,98 & 1,29 \\
\hline Công thức 4 & 10,2 & 7,8 & 5,87 & 3,6 & 2,13 & 0,92 \\
\hline$C V(\%)$ & 4,80 & 9,40 & 11,90 & 16,70 & 14,90 & 2,50 \\
\hline$L S D_{0,05}$ & 0,98 & 1,44 & 1,37 & 1,38 & 0,87 & 0,05 \\
\hline
\end{tabular}

Ghi chú: Công thức 1 (khoanh cành cấp 2 vào ngày 5 tháng 12); Công thức 2 (khoanh cành cấp 2 vào ngày 15 tháng 12); Công thức 3 (khoanh cành cấp 2 vào ngày 25 tháng 12); Công thức 4 (đối chứng không khoanh)

3.3. Ảnh hưởng của thời điểm khoanh vỏ đến các yếu tố cấu thành năng suất và năng suất

Áp dụng biện pháp khoanh vỏ có ảnh hưởng lớn đến tỷ lệ đậu quả, đồng thời cũng có ảnh hưởng đến năng suất và các yếu tố cấu thành năng suất trên bưởi Xuân Vân. Kết quả theo dõi về ảnh hưởng của các công thức khoanh vỏ đến năng suất và các yếu tố cấu thành năng suất bưởi Xuân Vân được trình bày tại bảng 03 .

Số liệu cho thấy, khoanh vỏ đã có những ảnh hưởng đến số quả/cây, các công thức 1 , công thức 2 , công thức 3 trong năm 2018 và năm 2019 đều có số quả trên cây cao hơn công thức đối chứng ở mức độ tin cậy $95 \%$. Trong đó công thức 3 có số quả/cây cao nhất, năm 2018 đạt 130 quả/cây, năm 2019 đạt 128,7 quả/cây. Công thức 2 có số quả/cây đứng thứ 2 , năm 2018 công thức 2 đạt 122 quả/cây, năm 2019 đạt 121,7 quả/cây. Công thức 1 có số quả/cây đứng thứ 3 , năm 2018 công thức 1 đạt 116,6 quả/cây, năm 2019 đạt 118,3 quả/cây.

Khối lượng quả/cây cũng là một trong những yếu tố cấu thành năng suất bưởi Xuân Vân, kết quả theo dõi khối lượng quả ở các công thức khoanh vỏ cho thấy, khối lượng quả ở các công thức dao động từ $0,912-0,949 \mathrm{~kg} / q u a ̉$ (năm 2018), từ $0,908-0,938$ kg/quả (năm 2019). Năng suất thực thu của các công thức 1, công thức 2 và công thức 3 đều cao hơn công thức đối chứng ở mức độ tin cậy 95\%. Năm 2018 công thức 3 đạt năng suất $120,1 \mathrm{~kg} /$ cây, tiếp theo là công thức 2 đạt năng suất $115,7 \mathrm{~kg} / \mathrm{cây}$, công thức 1 đạt năng suất 109,4 kg/cây và cuối cùng là công thức đối chứng đạt năng suất $89,1 \mathrm{~kg} / \mathrm{cây}$. Tương tự như vậy năm 2019 các công thức khoanh vỏ đều đạt năng suất cao hơn so với công thức đối chứng ở mức độ tin cậy $95 \%$, năng suất các công thức khoanh vỏ dao động từ 109,8 - 118,4 kg/cây, trong đó công thức 3 đạt năng suất $118,4 \mathrm{~kg} / \mathrm{cây}$, tiếp theo là công thức 2 đạt năng 
suất 114,2 kg/cây, công thức 1 đạt năng suất 109,8 $\mathrm{kg}$ /cây, và cuối cùng là công thức đối chứng đạt năng suất $81,4 \mathrm{~kg} / \mathrm{cây}$. Kết quả theo dõi các chỉ tiêu ở các công thức khoanh vỏ trong năm 2018 và năm 2019 cho thấy, thời điểm thích hợp để bưởi Xuân Vân ra hoa và cho năng suất cao nhất là ngày 25 tháng 12 , tuy nhiên để bưởi Xuân Vân ra hoa sớm đạt năng suất cao còn phụ thuộc vào rất nhiều các yếu tố như: thời tiết, dinh dưỡng và các biện pháp kỹ thuật khác.v.v..

\section{Bảng 03. Ảnh hưởng của thời điểm khoanh vỏ đến yếu tố cấu thành năng suất và năng suất bưởi Xuân Vân tại huyện Yên Sơn - Tuyên Quang}

\begin{tabular}{|c|c|c|c|c|c|c|}
\hline \multirow[b]{2}{*}{ Công thức } & \multicolumn{3}{|c|}{ Năm 2018} & \multicolumn{3}{|c|}{ Năm 2019} \\
\hline & 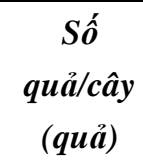 & $\begin{array}{c}\text { Khối luọng } \\
\text { quả } \\
\text { (kg/quả) }\end{array}$ & $\begin{array}{c}\text { Năng suất } \\
\text { (kg/cây) }\end{array}$ & $\begin{array}{c}\text { Số } \\
q u a ̉ / c a ̂ y\end{array}$ & $\begin{array}{c}\text { Khối } \\
\text { luộng quả } \\
\text { (kg/quả) }\end{array}$ & $\begin{array}{c}\text { Năng suất } \\
\text { (kg/cây) }\end{array}$ \\
\hline Công thức 1 & 116,6 & 0,938 & 109,4 & 118,3 & 0,928 & 109,8 \\
\hline Công thức 2 & 122,0 & 0,949 & 115,8 & 121,7 & 0,938 & 114,2 \\
\hline Công thức 3 & 130,0 & 0,924 & 120,1 & 128,7 & 0,920 & 118,4 \\
\hline Công thức 4 & 97,7 & 0,912 & 89,1 & 89,7 & 0,908 & 81,4 \\
\hline$C V(\%)$ & 4,40 & 2,80 & 4,60 & 2,70 & 2,60 & 3,20 \\
\hline$L S D_{0,05}$ & 10,13 & 0,05 & 8,58 & 6,12 & 0,04 & 6,69 \\
\hline
\end{tabular}

Ghi chú: Công thức 1(khoanh cành cấp 2 vào ngày 5 tháng 12); Công thức 2 (khoanh cành cấp 2 vào ngày 15 tháng 12); Công thức 3 (khoanh cành cấp 2 vào ngày 25 tháng 12); Công thức 4 (đối chứng không khoanh)

\section{KÊT LUẬN}

\subsection{Kết luận}

Thời điểm khoanh vỏ đã có ảnh hưởng rõ rệt đến thời điểm ra hoa, tỷ lệ đậu quả và năng suất bưởi Xuân Vân Khoanh vỏ vào ngày 25 tháng 12 hàng năm đã làm cho bưởi Xuân Vân ra hoa sớm hơn từ 1 - 7 ngày so với công thức đối chứng. Khoanh vỏ vào ngày 25 tháng 12 hàng năm đã làm tăng tỷ lệ đậu quả bưởi Xuân Vân từ 1,25 - 1,29 \% cao hơn công thức đối chứng từ $0,37-0,38 \%$. Khoanh vỏ ngày 25 tháng 12 đã làm tăng năng suất bưởi Xuân Vân từ 118,4 - 120,1 $\mathrm{kg} / \mathrm{cây}$, cao hơn so với đối chứng từ 31,0 - 37,0 kg/cây

\section{2. Đề nghị}

Cần có những nghiên cứu về thời điểm khoanh vỏ trên các giống bưởi khác nhau tại tỉnh Tuyên Quang để có cơ sở khẳng định chắc chắn sự ảnh hưởng của thời điểm khoanh vỏ đến thời gian ra hoa, tỷ lệ đậu quả và năng suất của các giống bưởi.

\section{TÀI LIỆU THAM KHẢO}

1. Trans Van Hau (2009), The method to stimulate flowering, Can Tho University.
2. Nguyen Quoc Hung (2013), Research on production status and technical measures to improve productivity and quality of pomelos in the direction of Vietnam GAP, in Hanoi, Final report of research topic.

3. Nguyen Huu Tho (2015), Research on agrobiological characteristics and some technical measures for Dien grapefruit variety (Citrus Grandis) in Thai Nguyen province, $\mathrm{PhD}$ thesis in agriculture.

4. Kim W. S and Chung S. J (2000), "Effect of GA3, ethephon, girdling and wiring treatment on the berry enlargement and maturity of ' Himrod grape", $J$. Korean Soc. Hort. Sci. (41), pp. 75 - 77.

5. Wang, X. C. and Zheng, R. W (1997), “ Study of the effects of girdling and applying cultar on the vigorous low - fruited apple tree", China Fruits (1), pp. 19 - 20 . 


\section{Study the effects of girdling time to flowering time, fruit setting and yield of Xuan Van pomelo in Tuyen Quang province}

Vi Xuan Hoc, Nguyen Thi Xuyen, Pham Thi Mai Trang, Nguyen Thi Thu Hien

\begin{tabular}{l}
\hline Article info \\
\hline Recieved: \\
21/7/2020 \\
Accepted: \\
12/8/2020 \\
\hline
\end{tabular}

Keywords:

Girdling, fruit setting, yields Xuan Van pomelo

\begin{abstract}
Xuan Van pomelo originated in Xuan Van commune, Yen Son district, Tuyen Quang province, Xuan Van pomelo is a sweet early - ripening. Currently, Xuan Van pomelo is not only being identified as one of the strongest crop plants in Tuyen Quang province, but also it is capable of developing in the Northern midland of mountainous provinces. Xuan Van pomelo has large numbers of flowers, but the rate of fruiting is low because of adverse factors during the flowering period. In order to regulate the flowering process and increase fruiting rate, the studies on the time of girdling of Xuan Van pomelo showed that: girdling on December 25 every year Xuan Van pomelo flowering earlier from 1 to 7 days, increased the rate of fruit bearing from 31.3 to $35.8 \%$, the fruit yield reached the highest (from 31.1 to $34.3 \mathrm{~kg}$ fruit/tree), the difference was statistically significant at $95 \%$ confidence level. Girdling on December 25 every year has a pronounced deciduous effect in adjusting flowering time, raising fruiting rate, thereby improving the yield of Xuan Van pomelo.
\end{abstract}

